\title{
Testing the possibility of leaching salt debris obtained from underground excavations
}

\author{
Piotr Pierzyna ${ }^{1}$, Marcin Popczyk $^{1}$, and Tomasz Suponik ${ }^{1^{*}}$ \\ ${ }^{1}$ Faculty of Mining and Geology, Silesian University of Technology, Gliwice, Poland
}

\begin{abstract}
For many years, the Salt Mine in Bochnia has conducted the extraction and restructuring of underground working to obtain new touristic routes. The works generate a large amount of rock salt material, colloquially called "salt debris", containing a large part of silty minerals. Due to the large concentration of $\mathrm{NaCl}$ which constitutes a threat to the environment, the salt debris may only be stored at hazardous material dumps. This is why the mine works towards the industrial use of the material. Currently, the debris is used to produce a stabilizing backfill mixture that is used for filling the liquidated "Moszczenica" shaft. The liquidation shall be completed in the beginning of 2018 and to continue the management of the salt debris, the mine plans to leach it in a newly constructed system and the saturated brine obtained in the process shall be introduced to underground workings. The paper presents the results of semi-industrial tests of leaching intensity of salt debris, depending on the graining and the time taken by the process. The tests were conducted for three grain classes of the salt debris $(0-6,0-10$ and $0-20 \mathrm{~mm})$, at a temperature of $15^{\circ} \mathrm{C}$. The kinetic models of the process has been presented for the obtained results. The obtained results shall be used for the optimization of the operation of the future industrial system and shall be treated as input data for the automation control system.
\end{abstract}

\section{Introduction}

Within the process of revitalization of tourist routes and creating new underground heading elements, The Salt Mine in Bochnia obtains large amounts of waste material in the form of salt debris.

In case of active mines, the salt debris is successfully used to liquidate old and abandoned workings by backfilling [1]. In the inter-war period, in "Kałuszy" mine, wastes from the processing plant consisting of solid parts such as halite, anhydrite and silts (salt debris) as well as leach, served the production of a 1:2 mixture (solid parts:leach) that was used for the liquidation of underground workings [2]. As of today, the Salt Mine in Bochnia is not active and there are no possibilities to obtain new locations (abandoned workings) for depositing the debris in such a form. In special cases, crushed salt debris may also be used as a filling material, packing the underground waste dumps [3, 4]. German experience has exhibited that the material which constitutes insulating seals for radioactive and hazardous wastes dumps may also be based on the anhydrite salt debris. [5]. Due to the lack of underground waste dumps in Poland, this method of management of the salt debris may not be considered in the nearest time. An alternative for the above examples of management of salt debris, may be constituted by storing it on surface dumps. Due to the large concentration of the $\mathrm{NaCl}$ compound, however, such storage constitutes a hazard to the natural environment and should be stored at hazardous wastes dumps. Considering the above and the current possibilities of the "Bochnia" Salt Mine, the only possible method of management of the salt debris is its use in mining shaft backfilling technologies. For many years, this method was used in case of the completed liquidation of the "Siedlec" shaft and the pending liquidation of the "Moszczenica" shaft. The concept of the liquidation consists in filling the shaft tube with the backfilling mixture comprised of salt debris (Fig. 1), brine and hydraulic binding agent with proper characteristics and strength parameters $[6,7]$.

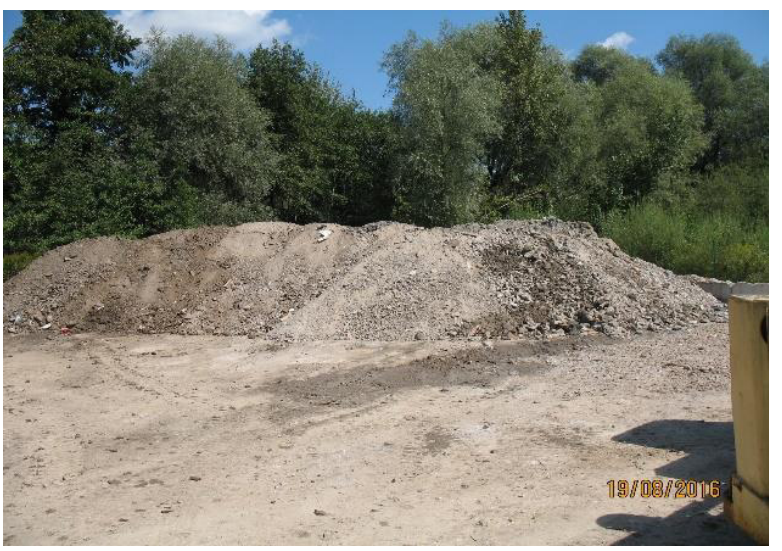

Fig. 1. Salt debris stored at a storage site by the "Moszczenica" shaft. Own source.

\footnotetext{
*Corresponding author: tomasz.suponik@polsl.pl
} 
The works are conducted in line with the assumed shaft liquidation plan, approved by the Mining Authority and financed by the Fund for Environmental Protection.

The use of the salt debris for the liquidation of the "Moszczenica" shaft will continue until the end of 2017. After that term, the Mine will face a problem of how to manage the salt debris that will continue to be retrieved from underground headings in a manner that would be safe for people and the environment. One of the possibilities to solve the problem is the method of leaching the salt debris proposed by the authors of the paper. The method allows to obtain a saturated brine which could be introduced to the inactive salt chambers of the mine. The process of introducing the brine to the rock mass is currently conducted by the mine, but brine pumped out from underground workings that is subsequently transported with water carts to the place of application is used for that purpose. The technology proposed by the authors shall allow for:

- ensuring the maximum use of the salt debris obtained in the revitalization works of the underground headings,

- eliminating the storage of the salt debris at surface dumps and thus eliminating the adverse impact on the environment,

- management of the produced saturated brine using the inactive underground workings.

Such a solution has not yet been applied in Poland and the concept should be concerned innovative. Currently the mine is at the stage of applying for financial measures from the National Fund for Environmental Protection for the construction of the salt debris leaching system in line with the technology described above and the investment is to be completed by the end of 2017 .

The aim of the study was to optimize the process of leaching salt debris in terms of grain size and process times. The brine from the installation of leaching will be directed through the existing well into the saline excavations which are isolated by natural rock layers. The condition and properties of the excavations and the surrounding rock allow for the safe functioning of the reservoir.

The paper presents the laboratory tests of possibilities of leaching salt debris, conducted on a semi-industrial scale at variable process parameters such as graining and leaching time. The saturation of the brine was determined by using two methods: indirectly, by measuring the density and by chemical analysis of the chlorides.

\section{Methods and materials}

\subsection{Physical characteristics of the salt debris}

The graining of the salt debris is highly variable. The grain-size analysis presented in Fig. 2. exhibits that approximately $50 \%$ of the salt debris grains corresponds to the size of approximately $16 \mathrm{~mm}$, while grains above $100 \mathrm{~mm}$ constitute approximately $10 \%$. The petrographic composition of the salt debris exhibits that it is composed mostly of three types of rocks, namely: the $\mathrm{NaCl}$ salt compound (30-50\%), silty rock (40-50\%) and anhydrite $(5-15 \%)$.

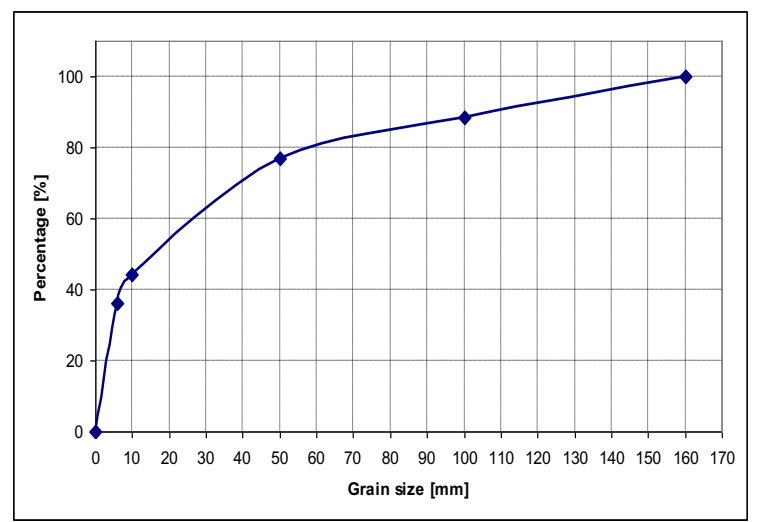

Fig. 2. Grain-size analysis of the salt debris.

\subsection{Leaching test facility}

The salt debris leaching tests facility is located at the technological hall owned by the Institute of Mining. The system is equipped with measurement and control devices such as: densimeter, flowmeters, temperature sensor and level sensors Aplisens S.A. The diagram of the installation is shown in Figure 3.

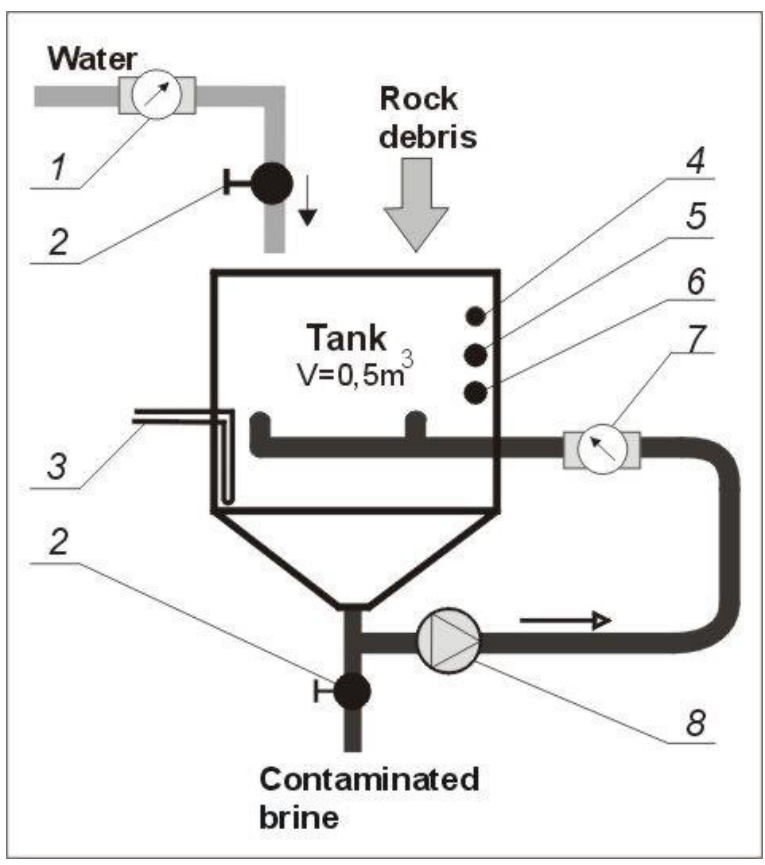

Fig. 3. The diagram of installation for leaching salt debris (1Flowmeter water, 2-Valve, 3-Heater, 4-Densimeter mixture, 5Level sensor, 6-Temperature sensor, 7-Flowmeter mixture, 8Pump).

Additionally, the tank is equipped with a heater allowing for the operation in temperature higher than the temperature of the supplied water. The diameter of the pipe fitted in the system $(100 \mathrm{~mm})$ fully correspond to the actual diameters that may be fitted in the future industrial system. The system operates as a closed cycle and is equipped with a PH65 Powen's rotary pump, which serves the mixing, pumping and exchange of the mixture in the tank. The piping is equipped with a series of flap valves 
allowing for the control of the flow through the selected diameters of the pipes.

The buffer of the system is constituted by an approximately $0.5 \mathrm{~m}^{3}$ tank, to which fresh water and salt debris are introduced. The view of the facility and the control system has been presented in Figs. 3 and 4.

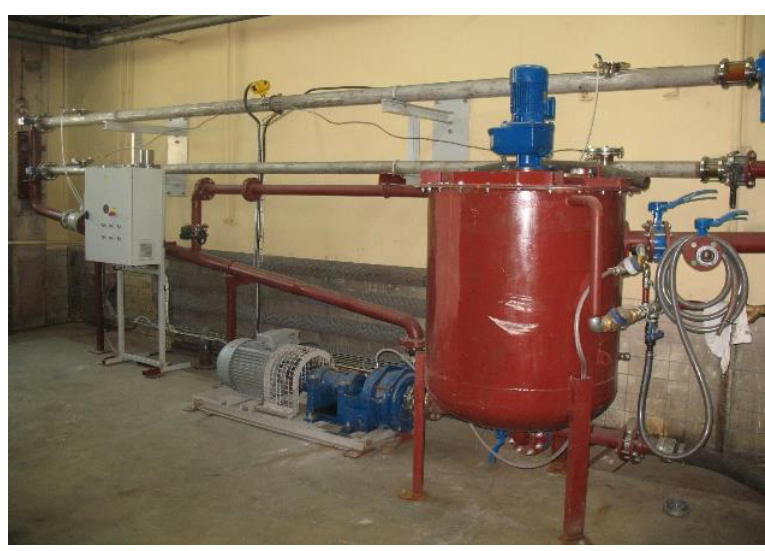

Fig. 4. General view of the salt debris leaching system.

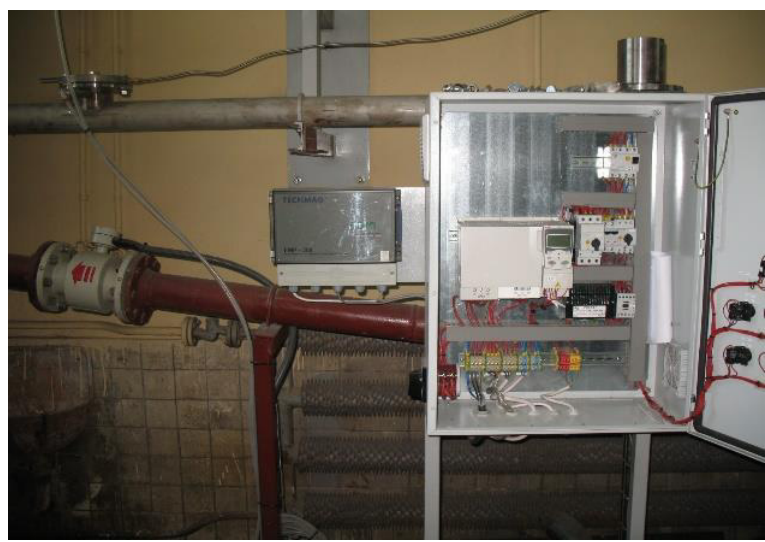

Fig. 5. The measurement and control device.

\subsection{Research methods}

The following research methods have been assumed in the semi-industrial scale tests. As the first step, municipal water at a temperature of approximately $12^{\circ} \mathrm{C}$ was introduced to the tank. The water was subsequently heated up to the temperature of $15^{\circ} \mathrm{C} \pm 0,5^{\circ} \mathrm{C}$ that was assumed in the tests. The heating process (stabilization of the leaching temperature) was conducted during the operation of the pump which pumped the water in the closed-cycle of the system.

After stabilizing the temperature of the entire system, the salt debris was introduced to the tank in the mass ratio of debris to water $0.8: 1$. This enabled the brine to reach saturation at a density of $1315 \pm 2 \mathrm{~g} / \mathrm{dm}^{3}$, in laboratory conditions. This value has been reached in the initial laboratory tests and corresponds to the density of saturated brine at a temperature of approximately $5^{\circ} \mathrm{C}$, contaminated by the post-leaching deposits consisting of mainly a clay.

The tests were conducted for three grain classes: 0 $20 \mathrm{~mm}, 0-10 \mathrm{~mm}$, and $0-6 \mathrm{~mm}$. The leaching temperature was set at $15^{\circ} \mathrm{C}$. During the course of leaching, the brine density in the tank was measured at fixed time intervals and it was sampled for laboratory tests to determine the level of chlorides. The density was measured by a densimeter placed in the tank. Every other test was verified by a pycnometer measurement in accordance to PN-EN 1097-7:2001. The obtained pycnometric densities were correlated with the readings of densimeter placed inside the system, which has been previously calibrated. Chloride level analysis was based on PN-ISO-9297.

The temperature, $\mathrm{pH}$ and the electrolytic conductivity were determined using electrometric methods (with the following meters: PORTAMESS $913 \mathrm{pH}$ with a SenTix 41 combination electrode; PORTAMESS 913 Cound). Also, the following determinations were made with regards to water:

- Concentrations of $\mathrm{Cr}^{6+} ; \quad \mathrm{SO}_{4}{ }^{2-}: \quad \mathrm{UV}-\mathrm{V}$ is Spectrophotometer DR5000 HachLange,

- Concentrations of $\mathrm{Ba}, \mathrm{Cr}, \mathrm{Zn}, \mathrm{Co}, \mathrm{Mg}, \mathrm{Mn}, \mathrm{Cu}, \mathrm{Ni}, \mathrm{Ca}$, Fe: ICP-AES using the JY 2000 spectrometer,

- Carbonate and total hardness: the analyses were made using a titration with ethylenediamineteraacetic acid (EDTA).

\subsection{Mathematical description}

Determining the kinetics of the leaching of salt solution from salt debris is essential in the modeling and process design on industrial scale. The initial concentration of $\mathrm{Cl}$ - ions in the aqueous solution used for kinetics testing was $0.084 \mathrm{~g} / \mathrm{dm} 3$. The tests were carried out at $15^{\circ} \mathrm{C}$.

The changes in the concentration of chlorides as a result of the leaching process were calculated in accordance with the equation:

$$
q_{t}=\frac{\left(C_{0}-C_{t}\right) \cdot V}{m}
$$

where :

$\mathrm{q}_{\mathrm{t}}$ - the amount of chlorides released from the mass of salt debris, $\mathrm{mg} / \mathrm{g}$,

$\mathrm{C}_{0}$ - the concentration of chlorides in saturated solution $\left(187.15 \mathrm{mg} / \mathrm{dm}^{3}\right), \mathrm{mg} / \mathrm{dm}^{3}$,

$\mathrm{C}_{t}$ - The concentration of solution saturation by chlorides (difference in chloride concentrations in saturated solution $\left(187.15 \mathrm{mg} / \mathrm{dm}^{3}\right)$ and in unsaturated solution after the certain time of leaching), $\mathrm{mg} / \mathrm{dm}^{3}$,

$\mathrm{V}$ - the volume of water used in the test, $\mathrm{dm}^{3}$, $\mathrm{m}$ - the mass of salt debris used in the test, $\mathrm{kg}$.

In order to determine the mechanism of salt debris leaching and the factors limiting its speed, the two nonlinear kinetic models were used being the pseudo-1storder (eq. 2) and pseudo-2nd-order (eq.3) models.

$$
q_{t}=q_{e}\left(1-\exp \left(-k_{1} t\right)\right)
$$

where:

$\mathrm{q}_{\mathrm{t}}, \mathrm{q}_{\mathrm{e}}$ - The amount of chloride (mg) released from salt debris $(\mathrm{kg})$ to solution $\left(\mathrm{dm}^{3}\right)$ in time $\mathrm{t}(\mathrm{min})$ and after reaching saturation, respectively, $(\mathrm{mg} / \mathrm{g})$

$\mathrm{k}_{1}$ - rate coefficient of the 1 st order reaction $\left(\mathrm{min}^{-1}\right)$ 


$$
q_{t}=q_{e} \frac{q_{e} k_{2} t}{1+q_{e} k_{2} t}
$$

where:

$\mathrm{k}_{2}$ - rate coefficient of the 2 nd order reaction $\left(\mathrm{g} \cdot \mathrm{mg}^{-1}\right.$ $\left.\cdot \mathrm{min}^{-1}\right)$.

\section{Test results}

\subsection{Kinetics of the leaching process}

On the basis of the conducted tests concerning the leaching of salt debris on the semi-industrial scale with variable process parameters, the following measurements were obtained (Table 1). In case of brine contaminated with clay, which has a significant effect on the density of the mixture, the measurement of its density may be treated as an indirect measurement indicating the density of the brine itself. Before that, it is necessary to carry out laboratory tests of the brine mixture and clay density and the corresponding density of brine, which allows to determine the density of the mixture in saturated state. In the case of systems operating on an industrial scale the measurement of brine saturation using a densimeter under the conditions of heavy clay content in the salt debris may be appropriate, but in the laboratory conditions where greater accuracy is required, it is necessary to measure the level of chlorides.

Table 1. Leaching status of salt debris of different graining at $15^{\circ} \mathrm{C}$ in relation to time.

\begin{tabular}{|c|c|c|c|c|c|c|}
\hline \multirow{3}{*}{$\begin{array}{c}\text { Time } \\
\text { debris } \\
\text { leaching } \\
\text { min }\end{array}$} & \multicolumn{6}{|c|}{$\begin{array}{l}\text { Densities and level of } \mathrm{Cl}^{-} \text {chlorides for different } \\
\text { grain size }\end{array}$} \\
\hline & \multicolumn{2}{|c|}{$0-6 \mathrm{~mm}$} & \multicolumn{2}{|c|}{$0-10 \mathrm{~mm}$} & \multicolumn{2}{|c|}{$0-20 \mathrm{~mm}$} \\
\hline & $\underset{3}{\rho,} \rho_{3}$ & $\underset{\mathrm{g} / \mathrm{dm}^{3}}{\mathrm{Cl}^{-}}$ & $\underset{3}{\rho} \mathrm{g} / \mathrm{dm}$ & $\underset{\mathrm{g} / \mathrm{dm}^{3}}{\mathrm{Cl}^{-}}$ & $\underset{3}{\rho / d m}$ & $\underset{\mathrm{g} / \mathrm{dm}^{-}}{\mathrm{Cl}^{-}}$ \\
\hline 0 & 1002 & 0.084 & 1002 & 0.084 & 1002 & 0.084 \\
\hline 1 & 1295 & $\begin{array}{c}142.1 \\
5\end{array}$ & 1288 & $\begin{array}{c}121.8 \\
0\end{array}$ & 1256 & $\begin{array}{c}119.9 \\
8\end{array}$ \\
\hline 3 & 1309 & $\begin{array}{c}185.7 \\
7\end{array}$ & 1302 & $\begin{array}{c}181.8 \\
6\end{array}$ & 1277 & $\begin{array}{c}182.1 \\
1\end{array}$ \\
\hline 5 & 1316 & $\begin{array}{c}186.5 \\
0\end{array}$ & 1313 & $\begin{array}{c}185.8 \\
4\end{array}$ & 1293 & $\begin{array}{c}183.2 \\
9\end{array}$ \\
\hline 7 & 1314 & $\begin{array}{c}186.4 \\
5\end{array}$ & 1316 & $\begin{array}{c}186.8 \\
7\end{array}$ & 1304 & $\begin{array}{c}185.0 \\
8\end{array}$ \\
\hline 9 & 1314 & $\begin{array}{c}186.3 \\
9\end{array}$ & 1315 & $\begin{array}{c}186.5 \\
7\end{array}$ & 1315 & $\begin{array}{c}186.3 \\
1\end{array}$ \\
\hline 11 & 1315 & $\begin{array}{c}186.3 \\
5\end{array}$ & 1314 & $\begin{array}{c}186.5 \\
6\end{array}$ & 1316 & $\begin{array}{c}186.9 \\
5\end{array}$ \\
\hline 13 & 1314 & $\begin{array}{c}186.4 \\
8\end{array}$ & 1314 & $\begin{array}{c}186.5 \\
3\end{array}$ & 1316 & $\begin{array}{c}186.7 \\
9\end{array}$ \\
\hline 15 & 1316 & $\begin{array}{c}187.1 \\
5\end{array}$ & 1316 & $\begin{array}{c}186.4 \\
3\end{array}$ & 1317 & $\begin{array}{c}186.7 \\
4\end{array}$ \\
\hline
\end{tabular}

The leaching process was carried out in a closed circuit at a site with a buffer tank with a capacity of approximately $0,5 \mathrm{~m}^{3}$ using a $\mathrm{PH}-65$ pump with a capacity of approximately $30-35 \mathrm{~m}^{3} / \mathrm{h}$, which allowed for a onefold change in tank volume per minute. As can be seen in Table 1, leaching time for the brine from salt debris also decreases as the debris grain size decreases. The shortest leaching time of about $5 \mathrm{~min}$ was observed in the sample with $0-6 \mathrm{~mm}$ debris graining. The longest leaching time of about $9 \mathrm{~min}$ was observed in the sample of $0-20 \mathrm{~mm}$ debris graining. The leaching process using the centrifugal pump is characterised by a high intensity from the beginning. Already in the first minute we obtain the mixture density in the range from $1256 \mathrm{~g} / \mathrm{dm}^{3}$ for graining of $0-6$ to $1295 \mathrm{~g} / \mathrm{dm}^{3}$ for graining of $0-6 \mathrm{~mm}$. These densities correspond to approximately $95-98 \%$ of full brine saturation. After that the intensity of the process decreases and in the next few minutes the mixtures very slowly increase in saturation to its maximum level.

Based on the results obtained, it should be concluded that the optimal conditions for leaching salt debris and for reaching saturation of the solution occur at a grain size of $0-6 \mathrm{~mm}$ and a process duration of $5 \mathrm{~min}$.

As it may be noted in Table 1, the level of $\mathrm{Cl}^{-}$chlorides determined in the laboratory environment increases along the increase of the mixture density. The concentration of chlorides in saturated brine was ca. $187 \mathrm{~g} / \mathrm{dm}^{3}$.

\subsection{Mathematical description of kinetics}

Figures $6,7,8$ present the kinetics of the release of chlorides into the aqueous solution from the salt debris. The results show that the solutions were saturated after approximately 5, 9 and 11 minutes, for grain classes 0-6, $0-10$ and $0-20 \mathrm{~mm}$, respectively. The fastest leaching proceeded within first 60 seconds of the process. Later the aqueous solutions have reached slowly the saturation.

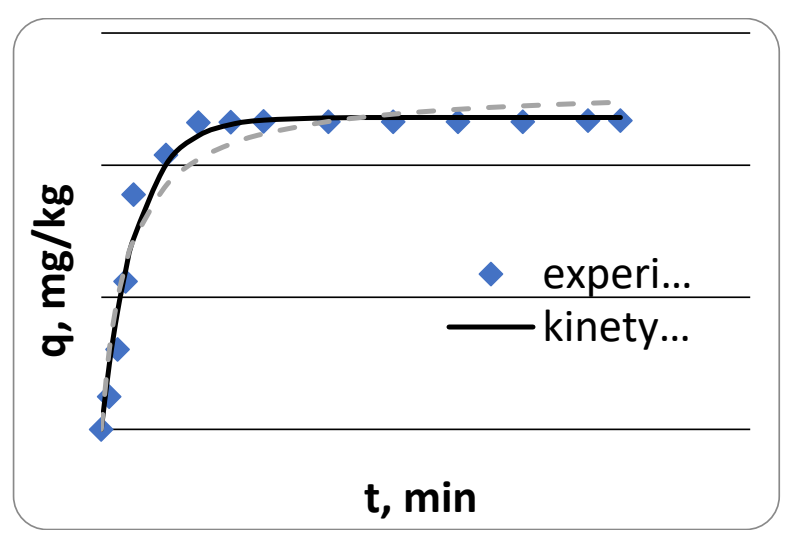

Fig. 6. The kinetics of the release of chlorides from the salt debris of grain size $0-6 \mathrm{~mm}$ to solution, $\mathrm{T}=15^{\circ} \mathrm{C}, \mathrm{C}_{\mathrm{o}}$ (saturated solution) $=187.15 \mathrm{mg} / \mathrm{dm}^{3}$.

The values of the rate coefficients $(\mathrm{k})$ and other parameters of the kinetic models as well as the determination coefficient values are shown in Table 2 . The highest value of $\mathrm{R}^{2}$ was the pseudo-1st-order model. The rate coefficients of this model were $0.9484,0.7484$, $0.7198 \mathrm{1} / \mathrm{min}$, for grain classes $0-6,0-10$ and $0-20 \mathrm{~mm}$, respectively. 


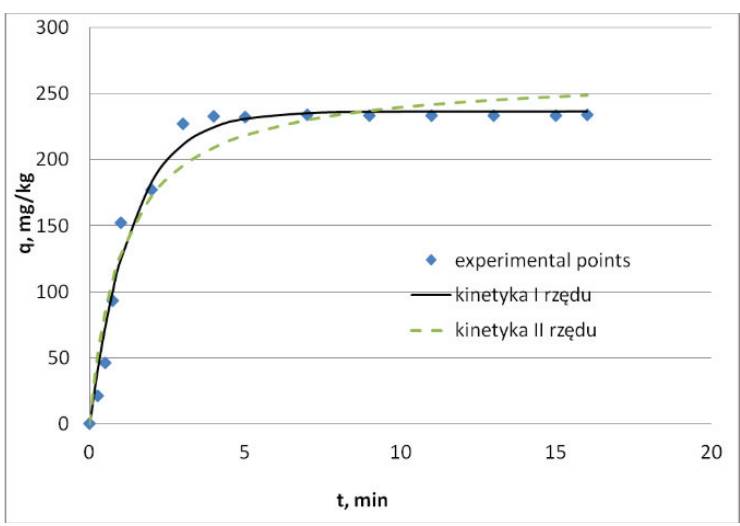

Fig. 7. The kinetics of the release of chlorides from the salt debris of grain size $0-10 \mathrm{~mm}$ to solution, $\mathrm{T}=15^{\circ} \mathrm{C}, \mathrm{C}_{\mathrm{o}}$ (saturated solution) $=187.15 \mathrm{mg} / \mathrm{dm}^{3}$.

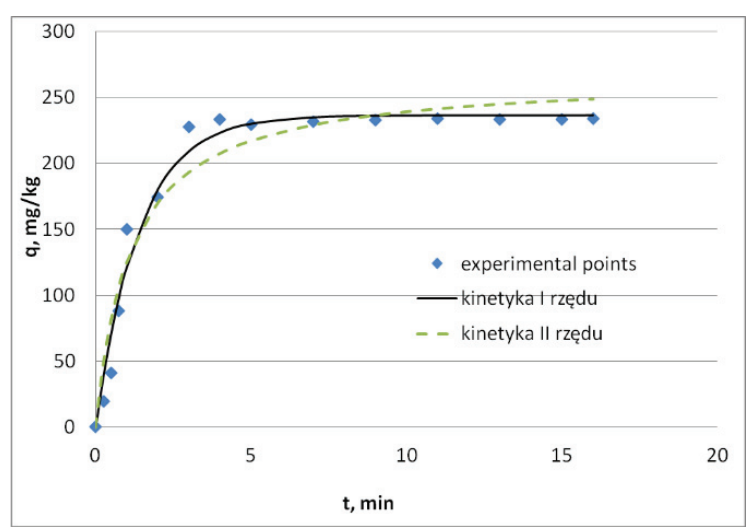

Fig. 8. The kinetics of the release of chlorides from the salt debris of grain size $0-20 \mathrm{~mm}$ to solution, $\mathrm{T}=15^{\circ} \mathrm{C}, \mathrm{C}_{\mathrm{o}}$ (saturated solution) $=187.15 \mathrm{mg} / \mathrm{dm}^{3}$.

Table 2. Parameters for kinetic models.

\begin{tabular}{|c|c|c|c|c|c|c|}
\hline \multirow{2}{*}{$\begin{array}{c}\text { grain } \\
\text { size, } \\
\mathbf{m m}\end{array}$} & \multicolumn{3}{|c|}{ The parameters of the kinetic model of: } \\
\cline { 2 - 7 } & \multicolumn{2}{|c|}{$\begin{array}{c}\text { pseudo-1st-order } \\
\text { reaction }\end{array}$} & \multicolumn{3}{c|}{$\begin{array}{c}\text { pseudo-2nd-order } \\
\text { reaction }\end{array}$} \\
\cline { 2 - 7 } & $\begin{array}{c}\mathrm{k}_{\mathrm{l}}, \\
\mathrm{min}^{-1}\end{array}$ & $\begin{array}{c}\mathrm{q}_{\mathrm{el}}, \\
\mathrm{mg} \cdot \mathrm{kg}^{-}\end{array}$ & $\mathrm{R}^{2}$ & $\begin{array}{c}\mathrm{k}_{\mathrm{II}}, \\
\mathrm{kg} \cdot \mathrm{mg}^{-} \\
{ }^{1} \cdot \mathrm{min}^{-1}\end{array}$ & $\begin{array}{c}\mathrm{q}_{\mathrm{eII}}, \\
\mathrm{mg} \cdot \mathrm{kg}^{-}\end{array}$ & $\mathrm{R}^{2}$ \\
\hline $0-6$ & 0.9484 & 236.1 & 0.9950 & 0.0047 & 230.3 & 0.9885 \\
\hline $0-10$ & 0.7484 & 236.5 & 0.9955 & 0.0035 & 265.1 & 0.9893 \\
\hline $0-20$ & 0.7198 & 236.5 & 0.9947 & 0.0033 & 266.2 & 0.9883 \\
\hline
\end{tabular}

\subsection{Brine chemical tests}

The main purpose of leaching of salt debris is to obtain saturated brine, which can be introduced to the underground workings through the hole from the surface. In order to employ this solution it is necessary to obtain in the process of leaching of salt debris- the saturated brine. An additional requirement is that the brine obtained from the system and introduced into the rock is characterised by a similar chemical composition to the brine currently pumped from the workings in the other parts of the mine Bochnia.

The results of the studies presented in Table 3 were performed for brine obtained under optimum leaching conditions, i.e. for particle size and process time of 0-6 $\mathrm{mm}$ and $5 \mathrm{~min}$, respectively. As can be seen in this table, $\mathrm{pH}$ of brine and post-leaching brine was 7.06 and 6.75 respectively, and the electrolytic conductivity and concentration with chlorides and sulphates were 180.4 $\mathrm{mS} / \mathrm{cm}, 185.133 \mathrm{~g} / \mathrm{dm}^{3}, 3.750 \mathrm{~g} / \mathrm{dm}^{3}$ and $178.3 \mathrm{mS} / \mathrm{cm}$, $187.156 \mathrm{~g} / \mathrm{dm}^{3}, 1.750 \mathrm{~g} / \mathrm{dm}^{3}$ respectively. Both types of brine are characterised by low carbonate hardness and very high concentration of calcium and magnesium. Low levels of barium, zinc, copper, manganese, and iron were also identified, with the concentration of iron in the brine probably being higher than presented in Table 3 , as the tests were conducted a few days after obtaining the samples, and a brown hydroxide sediment was observed at the bottom of the tank. The concentration of other analysed metals was below the limit of quantification.

In summary, both analysed types of brine exhibit the same chemical composition and are characterised by very high concentration with chlorides and very high noncarbonate hardness represented by sulphates and chlorides, mainly of calcium and magnesium.

Table 3. Test results of brine from Salt Mine in Bochnia workings and brine obtained as a result of salt debris leaching.

\begin{tabular}{|c|c|c|}
\hline Substance/parameter, unit & $\begin{array}{c}\text { Brine } \\
\text { from Salt } \\
\text { Mine in } \\
\text { Bochnia }\end{array}$ & $\begin{array}{c}\text { Brine } \\
\text { obtained from } \\
\text { salt debris } \\
\text { leaching }\end{array}$ \\
\hline $\mathrm{pH}$ & 7.06 & 6.75 \\
\hline Conductivity, mS/cm & 180.4 & 178.3 \\
\hline $\mathrm{Cl}^{-}, \mathrm{g} / \mathrm{dm}^{3}$ & 185.133 & 187.156 \\
\hline $\mathrm{SO}^{2-}, \mathrm{g} / \mathrm{dm}^{3}$ & 3.750 & 1.750 \\
\hline $\begin{array}{c}\text { Carbonate hardness, mmol } \\
(\mathrm{Ca}+\mathrm{Mg}) / \mathrm{dm}^{3}\end{array}$ & 1.41 & 0.90 \\
\hline $\begin{array}{c}\mathrm{Total} \mathrm{hardness,} \mathrm{mmol} \\
(\mathrm{Ca}+\mathrm{Mg}) / \mathrm{dm}^{3}\end{array}$ & 77.90 & 65.85 \\
\hline $\mathrm{Cr}{ }^{6+}, \mathrm{mg} / \mathrm{dm}^{3}$ & $<0.01$ & $<0.01$ \\
\hline $\mathrm{Temperature},{ }^{\circ} \mathrm{C}$ & 19.2 & 19.6 \\
\hline $\mathrm{Ba}, \mathrm{mg} / \mathrm{dm}^{3}$ & 32 & 22 \\
\hline $\mathrm{Cr}, \mathrm{mg} / \mathrm{dm}^{3}$ & $<0.01$ & $<0.01$ \\
\hline $\mathrm{Zn}, \mathrm{mg} / \mathrm{dm}^{3}$ & 0.94 & 0.72 \\
\hline $\mathrm{Co}, \mathrm{mg} / \mathrm{dm}^{3}$ & $<0.006$ & $<0.006$ \\
\hline $\mathrm{Mg}, \mathrm{mg} / \mathrm{dm}^{3}$ & 1021.44 & 792.83 \\
\hline $\mathrm{Mn}, \mathrm{mg} / \mathrm{dm}^{3}$ & 2.684 & 1.678 \\
\hline $\mathrm{Cu}, \mathrm{mg} / \mathrm{dm}^{3}$ & 0.25 & 0.34 \\
\hline $\mathrm{Ni}, \mathrm{mg} / \mathrm{dm}^{3}$ & $<0.006$ & $<0.006$ \\
\hline $\mathrm{Ca}, \mathrm{mg} / \mathrm{dm}^{3}$ & 1426.84 & 1322.64 \\
\hline $\mathrm{Fe}, \mathrm{mg} / \mathrm{dm}^{3}$ & 0.08 & 1.08 \\
\hline
\end{tabular}

\section{Conclusion}

The system used for testing operated in a hydraulically closed loop using a buffer tank of approximately $0.5 \mathrm{~m} 3$, a set of connection pipes, and a PH-65 pump with a capacity of approximately $30-35 \mathrm{~m}^{3} / \mathrm{h}$, allowing for onefold change in tank volume per minute (approximately). At fixed intervals during the testing the density of the mixture and the level of chlorides were measured, and on that basis the degree of brine saturation was determined. Based on the results of the tests, it can be concluded that: 
1. the leaching system used is characterised by a high leaching efficiency, which allows to obtain approximately $95 \%$ saturation level only after one minute,

2. the maximum density achieved during the leaching of salt debris was within the range from 1314 to $1317 \mathrm{~g} / \mathrm{dm}^{3}$. Conducted tests on the levels of $\mathrm{Cl}^{-}$ indicated their value at approximately $187.15 \mathrm{~g} / \mathrm{dm}^{3}$ at these densities. Comparing this value to the results of levels of $\mathrm{Cl}-$ in the amount of $185.13 \mathrm{~g} / \mathrm{dm} 3$ in saturated brine supplied from the mine workings, it must be concluded that in the system the mixture achieved the state of full saturation,

3. with the increase of graining of salt debris the time required to saturate the brine increases,

4. the pseudo-1st-order model described best the kinetics of the release of chlorides from the salt debris to aqueous solution. The value of R2 ranged from 0.9947 to 0.9955 . The rate coefficients of this model were $0.9484,0.7484,0.7198 \mathrm{l} / \mathrm{min}$, for grain classes $0-6,0$ 10 and $0-20 \mathrm{~mm}$, respectively.

5. the optimal conditions for leaching salt debris and for reaching saturation of the solution occur at a grain size of $0-6 \mathrm{~mm}$ and a process duration of $5 \mathrm{~min}$. The brine obtained under such conditions had a similar chemical composition to the brine from the mine. The brine from the installation of leaching will be directed through the well into the saline excavations which are isolated by natural rock layers. The condition and properties of the excavations and the surrounding rock allow for the safe functioning of the reservoir.

In summary the results of leaching time tests, from the point of view of their applicability in the design of future industrial systems constructed by mines, are positive and fully acceptable by the mine. The debris leaching technology presented by the authors will allow to:

- ensure the full use of salt debris obtained from revitalisation works of underground workings,

- eliminate the storing needs of salt debris in landfill sites, therefore cancelling the negative environmental impact,

- manage the saturated brine produced in inactive underground workings.
This solution has as of yet never been applied and the idea should be seen as innovative. Currently the mine is in the process of applying for funding from the National Environmental Protection Fund for the construction of a salt debris leaching system according to the technology presented above, and the commencing of the investment is scheduled for the end of 2017.

\section{References}

1. K. Poborska-Młynarska, Przeg. Górn. 12, 140-146 (2015)

2. K. Poborska-Młynarska, W. Andrusikiewicz, Geologia 36, 3, 273-285 (2010)

3. C. Ludeling, W. Minkley, ARMA 2, 1395-1402 (2014)

4. M. B. Dusseault, D. Mraz, J. Unrau, C. Fordham, ARMA 77, 313-322 (1985)

5. H. Mischo, Glueckauf-Forschungshefte 63, 126$138+118$ (2002)

6. J. S. Mahlaba, E. P. Kearsley, R. A. Kruger, Min. Eng. 24, 923-929 (2011)

7. F. Plewa, M. Popczyk, P. Pierzyna, T. Migdas, Polit. Energ. 14, 317-323 (2011) 